\title{
Estimation of Value-at-Risk Adjusted under the Capital Asset Pricing Model Based on ARMAX-GARCH Approach
}

\author{
Sukono $^{1 *}$, Eman Lesmana ${ }^{1}$, Dwi Susanti ${ }^{1}$, Herlina Napitupulu $^{1}$, And \\ YUYUN HidAYAT ${ }^{2}$ \\ ${ }^{1}$ Department of Mathematics, Faculty of Mathematics and Natural Sciences, \\ Universitas Pajadjaran, Indonesia \\ ${ }^{2}$ Department of Statistics, Faculty of Mathematics and Natural Sciences, Universitas \\ Padjadjaran, Indonesia \\ Email: sukono@unpad.ac.id; eman.lesmana@unpad.ac.id; dwi.susanti@unpad.ac.id; \\ napitupuluherlina@gmail.com; yuyunhidayat@unpad.ac.id
}

*Corresponding author: sukono@unpad.ac.id

\begin{abstract}
Investors having an understanding of investment statistics are important. Especially quantitative tools related to investment risk measurement. Value-at-Risk (VaR) Adjusted is for measuring investment risk, which assumes that returns are not normally distributed. This paper intends to measure investment risk based on VaR Adjusted or called Modified Value-at-Risk (MVaR) under the Capital Asset Pricing Model (CAPM). Here assumes the return level of the market index has a nonconstant average and there is a long memory effect. The average of the return of the market index is estimated using ARFIMA models. It is also assumed that the stock risk premium correlates with market risk premiums, and stock risk premiums some time before. The correlation will be analyzed using the ARMAX-GARCH model approach. The MVaR was then formulated based on the CAPM with ARMAXGARCH models approach.To measure the performance of MVaR that has been formulated is done with back testing. Back testing is carried out based on the Lopez II method. As a case study, analyzed some data on 10 stocks that are marketed on the Indonesian stock exchange. Based on the research results that the market index return risk premium significantly follows the ARFIMA model, and the 10 stocks risk premium significantly follows the ARMAX-GARCH model. Based on the results of back testing calculations indicate that the Value-at-Risk Adjustedor Modified Value-at-Risk is very suitable to be used to measure investment risk in the 10 stocks analyzed.

Kata kunci: Value-at-Risk Adjusted, Capital Asset Pricing Model, ARMAX, GARCH, Lopez II.
\end{abstract}

2000 Mathematics Subject Classification: C50, C58, C65 Received: 2019-02-15, accepted: 2019-06-18. 


\section{Introduction}

Risk is the difference between the expected return and its realization. The greater the deviationthe higher risk. Investors are willing to accept greater risks but must be compensated with investment opportunities to get a large return.The greater the desired results, the greater the risk [11], [15]. Conversely, the smaller the risk faced, the smaller the results that will be obtained. Investment decisions made by investors are based on the average rate of return and variance. However, lately the risk is more popularly measured using quantiles or often referred to as Value-at-Risk (VaR). Furthermore, this VaR is used to predict the risk of return on investment that are normally distributed. When a return asset (stock) is not normally distributed, risk is measured based onValue-at-Risk Adjusted or Modified VaR (MVaR) [4], [7] .

Stock return risk premiums are often influenced by the premium market risk returns. The correlation between the risk premium of market returns and the risk premium of stock returns can be explained by the Capital Asset Pricing Model (CAPM) regression [2], [5], [12] . So that CAPM regression can be used to determine the price of assets (stocks) at risk. Stock return risk premiums at a certain time other than influenced by the market index return risk premium, often also by the stock return risk premium some time before, and also the residuals at certain times and before [13].Such characteristics meet the characteristics of the $\mathrm{X}$ autoregressive moving average model (ARMAX) [1], [10]. The return of the market index often has an mean and volatility is non-constant, and there is even a long memory effect. Constant mean and volatility and long memory effects can thus be analyzed using time series approaches [8], [10], [16].

This paper analyzes the measure of the risk identified as Value-at-Risk Adjusted or Modified Value-at-Risk (MVaR), in which the shares analyzed are assumed to follow the CAPM form. Especially the nonstandard CAPM forms that follow the ARMAX model. It is also assumed that the market index return has an mean and volatility is non-constant, and there is a long memory effect.The mean and long memory effects will be estimated using the autoregressive fractionally integrated moving average (ARFIMA) approach, whereas for non-constant volatility it is estimated to use generally autoregressive conditional heteroscedastic (GARCH) model. MVaR value, then will be calculated based on CAPM regression that follows the ARMAX model. To evaluate the MVaR performance that has been generated based on the above method, it is done by back test. Back testing is done using the Lopez II method approach. This paper intends to measure MVaR of ten stocks are traded on stock exchanges in Indonesia using the method mentioned above.

\section{Methodology}

Suppose $P_{i t}$ and $r_{i t}$ successively stated stocks prices and returns $i(i=1, \ldots, N$ and $N$ the number of stocks analyzed), at the time $t(t=1, \ldots, T, T$ periode observasi data). Stocks return $r_{i t}$ calculated using equation $r_{i t}=\ln \left(P_{i t} / P_{i t-1}\right)$ [14], [17]. Furthermore, the return data is analyzed in the following sections.

2.1. Modeling the return index of market time ratio. Mean modeling. Identification of long memory effects on the data return of the market index $r_{m t}$. Identification is done using the rescale range $(\mathrm{R} / \mathrm{S})$ method or the Geweke and Porter-Hudak (GPH) methods. Estimation of fractional differentiation parameters $d_{m}$ (mstates market index), performed using the maximum likelihood method [3], [17]. Trust hose $(1-\alpha) 100 \%$ for $d_{m}$ that is $\hat{d}_{m}-z_{\alpha / 2} \cdot \sigma_{d_{m}}<d_{m}<\hat{d}_{m}+z_{1-\alpha / 2} \cdot \sigma_{d_{m}}$ with $\hat{d}_{m}$ estimator of $d_{m}$, and $z_{\alpha / 2}$ standard normal distribution percentile if given a level of significance $\alpha$. Suppose $d_{m}$ fractional differentiation to be tested by the hypothesis. Suppose also $\sigma_{d_{m}}$ standard deviation of $d_{m}$. Hypothesis testing is carried out against $H_{0}: \hat{d}_{m}=0$ Test against $H_{1}: \hat{d}_{m} \neq 0$ use $z_{d_{m}}=d_{m} / \sigma_{d_{m}}$. Test criteria are reject $H_{0}$ if the value of $z_{d_{m}}<z_{\alpha / 2}$ or $z_{d_{m}}>z_{1-\alpha / 2}$ [11], [17]. 
Modeling the return index of market time ratio:

$$
(1-B)^{d_{m}} r_{m t}=a_{m t},-0.5<d_{m}<0.5
$$

with $\left\{a_{m t}\right\}$ residual white noise sequence, and $B$ stated the backshift operator. If fractional differentiation series $(1-B)^{d_{m}} r_{m t}$ follow the ARMA $(p, q)$ model, then $r_{m t}$ called the autoregressive fractionally integrated moving average process with degree, and , or $\operatorname{ARFIMA}(p, d, q)$ [3], [17]. Model equation of $\operatorname{ARMA}(p, q)$ is

$$
r_{m t}=\psi_{m 0}+\sum_{g=1}^{p} \psi_{m g} r_{m t-g}+a_{m t}+\sum_{h=1}^{q} \theta_{m h} a_{m t-h},
$$

with $\psi_{m 0}$ constants and $\psi_{m g}(g=1, \ldots, p)$ and $\theta_{m h}(h=1, \ldots, q)$ parameter coefficient of the mean model of return market index $r_{m t}$. Assumed $\left\{a_{m t}\right\}$ residual white noise sequence that has an average of 0 and a certain variance $\sigma_{a_{m}}^{2}[10]$, [11].

The stages of the mean modeling process include: (i) model identification, (ii) do parameter estimation, (iii) carry out diagnostic tests, and (iv) do forecasting [7], [17].

Volatility modeling. Security return volatility modeling is done using generalized autoregressive conditional heteroscedastic (GARCH) models. Suppose $\mu_{m t}$ and $\sigma_{m t}^{2}$ successive mean and volatility of the market index return $r_{m t}$, at the period $t(t=1, \ldots, T$ and $T$ data observation period). Residual $a_{m t}$ the above has the equation $a_{m t}=r_{m t}-\mu_{m t}$. Volatility $\sigma_{m t}^{2}$ will follow the GARCH model with degrees $\eta$ and $n$ or written as $\operatorname{GARCH}(\eta, n)$, when:

$$
a_{m t}=\sigma_{m t} \varepsilon_{m t}, \sigma_{i t}^{2}=\alpha_{m 0}+\sum_{k=1}^{\eta} \alpha_{m k} a_{m t-k}^{2}+\sum_{l=1}^{n} \beta_{m l} \sigma_{m t-l}^{2}+\varepsilon_{m t},
$$

with $\alpha_{m 0}$ constants and $\alpha_{m k}(k=1, \ldots, \eta)$ and $\beta_{m l}(l=1, \ldots, n)$ parameters of the market index return volatility model of $r_{m t}$. Assumed $\left\{\varepsilon_{m t}\right\}$ random variables that are mutually independent and identical (iid) with an average 0 and variance $1, \alpha_{m 0}>0, \alpha_{m k} \geq 0, \beta_{m l} \geq 0$, and $\sum_{k=1}^{\max (\eta, n)}\left(\alpha_{m k}+\beta_{m k}\right)<1[8],[16]$.

The steps of volatility modeling are: (i) Performing an estimation of the mean model, (ii) Conducting an ARCH effect test, (iii) Performing a model identification, (iv) Performing an estimation of the volatility model, (v) Conducting diagnostic testing, and (vi ) Forecasting.

Use the mean model estimator (2) and the volatility model estimator (3), the forecasting is carried out aimed at calculating the mean $\hat{\mu}_{m t}=\hat{r}_{m T}(1)$ and variance $\hat{\sigma}_{m t}^{2}=\hat{\sigma}_{m T}^{2}(1)$, namely the forecasting - step forward after the time period to $T$ [17].

2.2. CAPM modeling with the ARMAX approach. The assumptions underlying the CAPM are used in the discussion in this section. Suppose $r_{i t}$ stocks return $i(i=1, \ldots, N$ and $N$ the number of stocks analyzed) at the period $t, r_{m t}$ return market index at the period $t$, and $r_{f t}$ risk-free asset return at the periode $t$. If assumed the risk-free asset return has an mean $\mu_{f}=E\left(r_{f t}\right)$ constant, and variance $\sigma_{f}^{2}=\operatorname{Var}\left(r_{f t}\right)=0$, then standard CAPM form is:

$$
r_{i t}-\mu_{f}=\omega_{i 0}+\varphi_{i 0}\left(r_{m t}-\mu_{f}\right)+u_{i t}
$$

. Coefficient parameter $\omega_{i 0}$ and $\varphi_{i 0}$ can be determined by applying the least squares method [1], [6], [9].

Referring to the ARMAX model $[1 ; 11]$, the CAPM equation approaches the ARMAX model can be expressed as:

$$
r_{i t}-\mu_{f}=\omega_{i 0}+\varphi_{i 0}\left(r_{m t}-\mu_{f}\right)+\sum_{l=1}^{L} \phi_{i l}\left(r_{i t-l}-\mu_{f}\right)+u_{i t}-\sum_{s=1}^{S} \lambda_{i s} u_{i t-s},
$$

with $L$ lag length for the stock risk premium, and $S$ lag length for residuals $u_{i t}$. Parameters of $\omega_{i 0}, \varphi_{i 0}, \phi_{i l}(l=1, \ldots, L)$ and $\lambda_{i s}(s=1, \ldots, S)$ can be determined by applying the maximum likelihood method. Through equation (4), average stock return can be estimated $i(i=1, \ldots, N$ and $N$ the number of stocks analyzed) at the period $t$, that is $\hat{\mu}_{i}$. While the variance estimator and kurtosis of stocks return $i$ at period $t$, namely $\hat{\sigma}_{i}^{2}$, and $\hat{K}_{i}$ estimated through the GARCH model from residual squares $u_{i t}^{2}$. 
2.3. Kurtosis of GARCH models of $u_{i t}^{2}$. In this section you intend to discuss the excess of kurtosis the GARCH(1,1) model. The same method can be applied to other GARCH models. A model discussed here is:

$$
u_{i t}=\sigma_{i t} \varepsilon_{i t}, \sigma_{i t}^{2}=\alpha_{i 0}+\alpha_{i 1} u_{i t-1}^{2}+\beta_{i 1} \sigma_{i t-1}^{2}+\varepsilon_{i t}
$$

with $\alpha_{i 0}>0, \alpha_{i 1} \geq 0, \beta_{i 1} \geq 0, \alpha_{i 0}>0$, and $\left\{\varepsilon_{i t}\right\}$ sequence of iid that satisfy:

$$
E\left(\varepsilon_{i t}\right)=0, \operatorname{Var}\left(\varepsilon_{i t}\right)=1, E\left(\varepsilon_{i t}^{4}\right)=K_{\varepsilon_{i}}+3
$$

where $K_{\varepsilon_{i}}$ excess of kurtosis of residuals $\varepsilon_{i t}$. Based on assumptions, it is obtained as follows:

- $\operatorname{Var}\left(u_{i t}\right)=E\left(\sigma_{i t}^{2}\right)=\frac{\alpha_{i 0}}{1-\left(\alpha_{i 1}+\beta_{i 1}\right)}$

- $E\left(u_{i t}^{4}\right)=\left(K_{\varepsilon_{i}}+3\right) E\left(u_{i t}^{4}\right)$ with $E\left(u_{i t}^{4}\right)$ exist.

Take the square of the volatility equation (5), obtained:

$$
\sigma_{i t}^{4}=\alpha_{i 0}^{2}+\alpha_{i 1}^{2} u_{i t-1}^{4}+\beta_{i 1}^{2} \sigma_{i t-1}^{4}+2 \alpha_{i 0} \alpha_{i 1} a_{i t-1}^{2}+2 \alpha_{i 0} \beta_{i 1} \sigma_{i t-1}^{2}+2 \alpha_{i 1} \beta_{i 1} \sigma_{i t-1}^{2} u_{i t-1}^{2}
$$

Taking expectations of equation (7) and using the two properties mentioned above, is obtained:

$$
E\left(\sigma_{i t}^{4}\right)=\frac{\alpha_{i 0}^{2}\left(1+\alpha_{i 1}+\beta_{i 1}\right)}{\left[1-\left(\alpha_{i 1}+\beta_{i 1}\right)\right]\left[1-\alpha_{i 1}^{2}\left(K_{\varepsilon_{i}}+2\right)-\left(\alpha_{i 1}+\beta_{i 1}\right)^{2}\right]}
$$

with $0 \leq \alpha_{i 1}+\beta_{i 1}<1$ and $1-\alpha_{i 1}^{2}\left(K_{\varepsilon_{i}}+2\right)-\left(\alpha_{i 1}+\beta_{i 1}\right)^{2}>0$. Excess of kurtosis of $u_{i t}$, if exist is:

$$
K_{u_{i}}=\frac{E\left(u_{i t}^{4}\right)}{\left[E\left(u_{i t}^{2}\right)\right]^{2}}-3=\frac{\left(K_{\varepsilon_{i}}+3\right)\left[1-\left(\alpha_{i 1}+\beta_{i 1}\right)^{2}\right]}{1-2 \alpha_{i 1}^{2}-\left(\alpha_{i 1}+\beta_{i 1}\right)^{2}-K_{\varepsilon_{i}} \alpha_{i 1}^{2}}-3
$$

According to Tsay [17], the excess of this kurtosis can be written more informative. First, look at the case $\varepsilon_{i t}$ normal distribution. In terms of $K_{\varepsilon_{i}}=0$, and algebraically can be shown that:

$$
K_{u_{i}}^{(g)}=\frac{6 \alpha_{i 1}^{2}}{1-2 \alpha_{i 1}^{2}-\left(\alpha_{i 1}+\beta_{i 1}\right)^{2}}
$$

Superscript (g) is to declare a Gaussian distribution. These results have two important implications: (a) Kurtosis $u_{i t}$ exist, if $1-2 \alpha_{i 1}^{2}-\left(\alpha_{i 1}+\beta_{i 1}\right)^{2}>0$, while (b) if $\alpha_{i 0}=0$, then $K_{u_{i}}^{(g)}=0$, indicates the $\operatorname{GARCH}(1,1)$ model does not contain a heavy tail [8], [16].

Next, look at the problem $\varepsilon_{i t}$ non Gaussian. Using previous results, obtained:

$$
K_{u_{i}}=\frac{K_{\varepsilon_{i}}-K_{\varepsilon_{i}}\left(\alpha_{i 1}+\beta_{i 1}\right)+6 \alpha_{i 1}^{2}+3 K_{\varepsilon_{i}} \alpha_{i 1}^{2}}{1-2 \alpha_{i 1}^{2}-\left(\alpha_{i 1}+\beta_{i 1}\right)^{2}-K_{\varepsilon_{i}} \alpha_{i 1}^{2}}=\frac{K_{\varepsilon_{i}}+K_{u_{i}}^{(g)}+\frac{5}{6} K_{\varepsilon_{i}} K_{u_{i}}^{(g)}}{1-\frac{1}{6} K_{\varepsilon_{i}} K_{u_{i}}^{(g)}}
$$

This is owned by all GARCH models with the provisions that have kurtosis. As an example, for $\beta_{i 1}=0$, resulting in an $\operatorname{ARCH}(1)$ model. So this is easy to get $K_{u_{i}}^{(g)}=6 \alpha_{i 1}^{2} /\left(1-3 \alpha_{i 1}^{2}\right)$ with $1>3 \alpha_{i 1}^{2}$, and excess kurtosis of $u_{i t}$ is:

$$
K_{u_{i}}=\frac{\left(K_{\varepsilon_{i}}+3\right)\left(1-\alpha_{i 1}^{2}\right)}{1-\left(K_{\varepsilon_{i}}+3\right) \alpha_{i 1}^{2}}-3=\frac{K_{\varepsilon_{i}}+2 K_{\varepsilon_{i}} \alpha_{i 1}^{2}+6 \alpha_{i 1}^{2}}{1-3 \alpha_{i 1}^{3}-K_{\varepsilon_{i}} \alpha_{i 1}^{2}}=\frac{K_{\varepsilon_{i}}+K_{u_{i}}^{(g)}+\frac{5}{6} K_{\varepsilon_{i}} K_{u_{i}}^{(g)}}{1-\frac{1}{6} K_{\varepsilon_{i}} K_{u_{i}}^{(g)}}
$$

Previous results have shown that the GARCH (1.1) coefficient model $\alpha_{i 1}$ has a very important role to determine behavior the tail of $u_{i t}$. If $\alpha_{i 1}=0$, then $K_{u_{i}}^{(g)}=0$ and $K_{u_{i}}=K_{\varepsilon_{i}}$. In this case, the behavior of the tail of $u_{i t}$ is commensurate with residual standardization $\varepsilon_{i t}$. However, if $\alpha_{i 1}>0$, then $K_{u_{i}}^{(g)}>0$ and $u_{i t}$ something process with a heavy tail [17].

For Student- $t$ standard distribution who has degrees of freedom $v$, obtained $E\left(\varepsilon_{i t}^{4}\right)=$ $6 /(v-4)+3$ if $v>4$. So, the excess of kurtosis of $\varepsilon_{i t}$ is $K_{\varepsilon_{i}}=6 /(v-3)$ for $v>4$. Excess of kurtosis of $u_{i t}$ become $K_{u_{i}}=\left[6+(v+1) K_{u_{i}}^{(g)}\right] /\left[v-4-K_{u_{i}}^{(g)}\right]$ with $1-2 \alpha_{i 1}^{2}(v-1) /(v-4)-$ $\left(\alpha_{i 1}+\beta_{i 1}\right)^{2}>0[17]$. 
2.4. Modified VaR normal. Cornish-Fisher expansion was used to determine percentiles of abnormal distributions. The Cornish-Fisher extension is intended to provide an adjustment factor for the estimated percentile of the distribution of non-normality, and for adjusted normality it is "small". Thus, expanded Cornish-Fisher can be used for adjustment of VaR when Profit / Loss (P / L) has a non-normality distribution [4], [11], [15].

Assume that $z_{\alpha}$ percentiles of standard normal distributions for confidence levels $\alpha$ (for example $z_{0.05}=-1.645$, and so on). So the Cornish-Fisher expansion is:

$$
z_{\alpha}+\frac{1}{6}\left(z_{\alpha}^{2}-1\right) S+\frac{1}{12}\left(z_{\alpha}^{3}-3 z_{\alpha}\right) K-\frac{1}{36}\left(2 z_{\alpha}^{3}-5 z_{\alpha}\right) S^{2}+\text { higher order terms }
$$

Where $S$ skewness and $K$ kurtosisa distribution Dowd [18]. If we omit the higher order terms because it is assumed that the effect is getting smaller than normality, the expansion becomes:

$$
z_{\alpha}+\frac{1}{6}\left(z_{\alpha}^{2}-1\right) S+\frac{1}{12}\left(z_{\alpha}^{3}-3 z_{\alpha}\right) K-\frac{1}{36}\left(2 z_{\alpha}^{3}-5 z_{\alpha}\right) S^{2}
$$

To use expansion, the percentile value is seen $z_{\alpha}$ from the standard normal probability distribution table. This is equivalent to adjusting the normal percentile $z_{\alpha}$ for skewness and or kurtosis [11], [16].

The existence of non-normality in stocks can be a guide to choosing a different portfolio with regard to assumptions. According to Dowd [18], Cornish-Fisher in 1937 developed a new measure in which risk was measured by standard deviation, skewness (for return asymmetry) and kurtosis (to return fat tailes).This measure is called Modified VaR (or MVaR), is similar to classic VaR. Referring to Dowd [18] and Sukono et al. [16], MVaR can be stated as follows:

$$
M V a R=-W_{0}\left\{\mu_{i}+\left(z_{\alpha}+\frac{1}{6}\left(z_{\alpha}^{2}-1\right) S_{i}+\frac{1}{24}\left(z_{\alpha}^{3}-3 z_{\alpha}\right) K_{i}-\frac{1}{36}\left(2 z_{\alpha}^{3}-5 z_{\alpha}\right) S_{i}^{2}\right) \sigma_{i}\right\}
$$

where $\mu_{i}$ mean, $\sigma_{i}$ standard deviation, $S_{i}$ skewness, $K_{i}$ kurtosis, of stock returns $i$ and $z_{\alpha}$ standard normal distribution percentile with a level of significance $\alpha$.

2.5. Back testing. According to Dowd [18], the Back test method can be done using a forecast evaluation approach introduced by Lopez in 1998. Suppose $r_{i t}$ is the loss rate (if negative) or profit (if positive), stocks return of $i(i=1, \ldots, N$ and $N$ the number of stocks analyzed), which is generated at the period $t$, and $V a R_{i t}$ is VaR forecast for stock returns $i$ at the period $t$, function of indicator loss for observation of stock returns in the period is given as follows:

$$
C_{i t}=\left\{\begin{array}{l}
f\left(r_{i t}, M V a R_{i t}\right), \text { jika } r_{i t}>M V a R_{i t} \\
g\left(r_{i t}, M V a R_{i t}\right), \text { jika } r_{i t} \leq M V a R_{i t}
\end{array}\right.
$$

where $f\left(r_{i t}, M V a R_{i t}\right)>g\left(r_{i t}, M V a R_{i t}\right)$.

Testing the null hypothesis needs to be done to show that the model $M V a R_{i t}$ is "best", can be used quadratic probability score (QPS) function given by:

$$
Q P S_{i}=\frac{2}{n} \sum_{j=1}^{n}\left(C_{i t}-p\right)^{2}
$$

where $p$ probability values that can be determined equal to the level of significance (usually at $5 \%$ ). The QPS value located between ranges [0,2], and the QPS value close to zero, is the best model Dowd [18]. Referring to equation (15), the range [0,2] shows that the number 0 is the minimum value that occurs when the whole $r_{i t} \leq M V a R_{i t}$, and numbers 2 is the maximum value occurs when the whole $r_{i t}>M V a R_{i t}$ [11], [16]. 


\section{RESUlts AND DISCUSSION}

The data analyzed included ten stocks consisting of stocks of INDF, DEWA, AALI, LSIP, ASII, TRUB, HDMT, BMRI, UNTR, and BBRI. Furthermore, the names of the stocks are symbolically successive $S_{1}$ up to $S_{10}$. Market index data used is the Composite Stock Price Index (CSPI), while as a risk-free asset used is a bond. The data is obtained from the website $h t t p$ : //www.finance.go.id. Using the stock price then the rate of return is calculated, and then used for the following average modeling and volatility. Data analysis was performed using MS Excel 2010, Eviews 8, and R software.

3.1. Mean modeling and volatility of data return market index. Estimation of the mean model of the Composite Stock Price Index (CSPI). In the analysis, the CSPI is used as a market index. Then the market index returns are calculated, and then identified long memory effects, estimated mean and volatility models.

Semua penulisan variabel ditulis dengan italic dengan index angka dalam century schoolbook, contoh, $X_{1}, \ldots, X_{n}$ dan $Y_{i}, i=1, \ldots n$. Gunakan tanda : untuk jelaskan arti variable dan $=$ jika variable itu bernilai sebuah angka atau persamaan. $N$ : jumlah data, $X=1$. Penulisan angka desimal dipisahkan dengan koma, dan bila lebih dari satu gunakan titik koma, ;, sebagai pemisah Misal $(0,234 ; 123,135 ; 4562,234)$. Semua parantheses ditulis dengan huruf Century Schoolbool, $\left(X_{1}, X_{2}\right),[i]$.

Identification of long memory effects. To identify long memory effects, it is done by estimating fractional differentiation parameters $d_{m}$ in equation (1). Estimates were made using the Geweke and Porter-Hudak methods, done using R-software. The estimation process produces fractional differentiation values $\hat{d}_{m}=0.3613183$; and standard deviation $\hat{\sigma}_{d_{m}}=0.1462239$. To ensure a long memory pattern, hypothesis testing is carried out $H_{0}: \hat{d}_{m}=0$ against $H_{1}: \hat{d}_{m} \neq 0$. Based on the results of calculations, statistics were obtained $z=5.86$. If the level of significance is determined $\alpha=0.05$, then from the standard normal distribution table the value of $z_{1-0.5 / 2}=$ 1.96 is obtained. Because of the value $z$ greater than value $z_{1-0.5 / 2}$, it can be concluded that the test results are significant. This shows that the market index returns the long memory effect. The $95 \%$ confidence interval for fractional differentiation parameters $\hat{d}_{m}$ determined by formula $\hat{d}_{m}-Z_{\alpha / 2} . \hat{\sigma}_{d_{m}}<d_{m}<\hat{d}_{m}+Z_{1-\alpha / 2} . \hat{\sigma}_{d_{m}}$, and the result is $0.074719<d_{m}<0.647917$. Because $\hat{d}_{m}$ located in intervals $-0.5<d_{m}<0.5$, concluded that $\hat{d}_{m}$ is true significant. The next step uses fractional differentiation values $\hat{d}_{m}=0.3613183$ for the estimation of the mean model and the volatility model.

Estimation of the mean model of CSPI. In this section Eviews 8 software is used for estimating the mean model. Fractional differentiated market index return data $\hat{d}_{m}=0.3613183$ the mean model will be estimated. The first stage, the return data is carried out identification and parameter estimation of the average model. Identification is done using an autocorrelation function (ACF) and partial autocorrelation function (PACF). Look at ACF and PACF patterns, a possible nominated model for the data return of the market index is the ARMA(1.1) model. Based on estimation results, it was found that ARMA(1. 1) model is significant. Referring to (2), the ARMA model (1.1) has an equation $r_{m t}=0.239800 r_{m t-1}$ $-0.997450 a_{m t-1}+a_{m t}$, or $\operatorname{ARFIMA}\left(1, \hat{d}_{m}, 1\right)$ model, where $\hat{d}_{m}=0.3613183$; with the equation $(1-0.239800 B)(1-B)^{0.3613183} r_{m t}=(1+0.997450 B) a_{m t}$.

The second stage, carried out a diagnostic test of the ARMA $(1,1)$ model. Diagnosis test is performed using correlogram from the residual of ARMA $(1,1)$ model, and also testing the Ljung-Box hypothesis. The test conducted ensures that the residual shock of the $\operatorname{ARMA}(1,1)$ model is white noise. Furthermore, a normality test for residuals is carried out $a_{m t}$. The test results show that $a_{m t}$ normal distribution. So that the model is quite significant.

Estimation of the volatility model CSPI. In this section Eviews 8 software is also used to estimate the volatility model. In the first phase, the detection of the existence of an autoregressive conditional heteroscedasticity $(\mathrm{ARCH})$ element on residuals $a_{m t}$ of ARMA $(1,1)$ model. Detection is done using the ARCH-LM test method. Detection results indicate that 
the calculation value $\chi^{2}$ (obs * R-Square) is 3.921869 with a probability of 0 or less than 0.05 , this indicates the existence of an ARCH element.

The third stage is to identify and estimate the volatility model. The volatility model used is the GARCH models referring the equation (3). Using a correlogram of residual squares $a_{m t}^{2}$, ACF chart decreases gradually after lag 1 , while the PACF chart decreases drastically after lag 1. Based on this, the tentative volatility model is defined as $\operatorname{GARCH}(1,1)$. Estimation of the volatility model is carried out simultaneously with the ARMA $(1,1)$ model. After repeated observations in estimating the volatility model, finally the best model was obtained by ARMA $(1,1)$-GARCH $(1,1)$. This model has a mean equation $r_{m t}=0.073579 r_{m t-1}-0.997326 a_{m t-1}+$ $a_{m t}$ and volatility equations $\sigma_{m t}^{2}=1.04 \times 10^{-8}+0.077409 a_{m t-1}^{2}+0.886862 \sigma_{m t-1}^{2}+\varepsilon_{m t}$. In the volatility modeling process it is also shown that the results of the ARCH-LM test, residual shock $\varepsilon_{m t}$ of $\operatorname{ARMA}(1,1)-\operatorname{GARCH}(1,1)$ models are white noise. Furthermore, mean and volatility estimator models can be used to forecast the values of $\hat{\mu}_{m t}=\hat{r}_{m t}(1)=0.0547027$ and $\hat{\sigma}_{m t}^{2}=\hat{\sigma}_{m t}^{2}(1)=0.0018864$; is a recursive 1-step forward forecasting.

3.2. Calculations of $M V a R_{i}$ andback testing. Before doing calculationsof $M V a R_{i}$, need to estimate the CAPM equation in the ARMAX-GARCH model approach first. Estimates are done using the help of Eviews 8 software. For each stock return $S_{1}$ up to $S_{10}$, the CAPM equation estimation of the ARMAX model approach is done by referring to equation (4). Residual from the ARMAX model, that is $u_{i t}$ then used to estimate the model of stock return data volatility $i(i=1, \ldots, 10)$,in ten stocks $S_{1}$ up to $S_{10}$. The volatility model is estimated using equation (3). The estimation of the resulting model is presented in Table- 1 column two (i.e.: "model"). Using the ARMAX-GARCH model estimator, then estimating the mean values and standard deviations for each stock $S_{1}$ up to $S_{10}$. The estimation results of the mean values and standard deviations are given in Table- 1 of the column $\hat{\mu}_{i}$ andcolumn $\hat{\sigma}_{i}$.

Through the volatility model, it is also used to estimate kurtosis values for each stock $S_{1}$ up to $S_{10}$. The estimation of kurtosis is calculated using equation (11). The calculation produces the kurtosis values for each stock $S_{1}$ up to $S_{10}$ given in Table-1 of the column $\hat{K}_{i}$. The GARCH model is a symmetry (Gaussian) model, therefore skewness is assumed to be equal to 0 . Thus, the calculation of Modified Value-at-Risk (MVaR) only involves parameters $\hat{\mu}_{i}, \hat{\sigma}_{i}$ and $\hat{K}_{i}$. Calculation of $M V a R_{i}$ for each stock $S_{1}$ up to $S_{10}$, done by referring to equation (13). The level of significance is set at $\alpha=0.05$; so that Look at the standard normal distribution table obtained $z_{0.05}=-1.645$. The calculation results $M V a R_{i}$ for each stock $S_{1}$ up to $S_{10}$ given in Tabel 1 of column $M V a R_{i}$.

After calculated $M V a R_{i}$ for each stock $S_{1}$ up to $S_{10}$, then back testing needs to be done. Back testing is done to measure the performance of the $M V a R_{i}$ model used. Back testing is done using equations (14) and (15), then the calculation results as shown in Tabel 1 of the column $Q P S_{i}$. The amount of $Q P S_{i}$ produced for each stock $S_{1}$ up to $S_{10}$, indicates that the values are in the range $[0,2]$, and tend to approach 0 . That means the model good enough as a measure of stock risk $S_{1}$ up to $S_{10}$. The amount of risk for each stock $S_{1}$ up to $S_{10}$ can be seen in Tabel 1 of the column $M V a R_{i}$. The size of the risk can be used as a consideration in investing in individual stocks, specifically stocks $S_{1}$ up to $S_{10}$.

\section{Conclusion}

This paper has discussed MVaR under CAPM using ARMAX-GARCH models. Based on the results of the identification, that the return of the market index has a long memory effect with a fractional differentiator estimator $\hat{d}_{m}=0.3613183$. In the data return the market index is fractionally differentiated, the mean and volatility follow the $\operatorname{ARFIMA}\left(1, \hat{d}_{m}, 1\right)-\operatorname{GARCH}(1,1)$ model. The mean market index estimated using the $\operatorname{ARFIMA}\left(1, \hat{d}_{m}, 1\right)-\operatorname{GARCH}(1,1)$ model, then used to form CAPM regression with ARMAX model approach, in stock return data $S_{1}$ up to $S_{10}$. Through the ARMAX-GARCH models produced, then used to estimate the mean 
TABEL 1. Model estimation results, calculations of $M V a R_{i}$ and Back Testing

\begin{tabular}{|c|c|c|c|c|c|c|}
\hline $\begin{array}{c}\text { Stocks } \\
\left(S_{i}\right) \\
\end{array}$ & Models & $\begin{array}{c}\text { Mean } \\
\left(\hat{\mu}_{i}\right)\end{array}$ & $\begin{array}{c}\text { Standar Dev. } \\
\left(\hat{\sigma}_{i}\right)\end{array}$ & $\begin{array}{c}\text { Kurtosis } \\
\left(\hat{K}_{i}\right)\end{array}$ & $M V a R_{i}$ & $Q P S_{i}$ \\
\hline$S_{1}$ & $\begin{array}{c}\operatorname{ARMAX}(1,1)- \\
\operatorname{GARCH}(1,1)\end{array}$ & 0.014364 & 0.037918 & 2.884 .444 & 0.047247 & 0.046195 \\
\hline$S_{2}$ & $\begin{array}{c}\operatorname{ARMAX}(1,1)- \\
\operatorname{ARCH}(2,1)\end{array}$ & 0.012776 & 0.027372 & 2.834 .820 & 0.031699 & 0.048987 \\
\hline$S_{3}$ & $\begin{array}{l}\operatorname{ARMAX}(1,1)- \\
\operatorname{GARCH}(1,1)\end{array}$ & 0.016777 & 0.030585 & 2.915 .390 & 0.032919 & 0.043281 \\
\hline$S_{4}$ & $\begin{array}{l}\operatorname{ARMAX}(1,1)- \\
\operatorname{GARCH}(1,1)-\mathrm{M}\end{array}$ & 0.013865 & 0.032695 & 2.876 .150 & 0.039259 & 0.034378 \\
\hline$S_{5}$ & $\begin{array}{l}\operatorname{ARMAX}(1,1)- \\
\operatorname{GARCH}(1,1)\end{array}$ & 0.019022 & 0.028064 & 2.924 .787 & 0.026578 & 0.038325 \\
\hline$S_{6}$ & $\begin{array}{l}\operatorname{ARMAX}(1,1)- \\
\operatorname{GARCH}(1,1)\end{array}$ & 0.037195 & 0.025206 & 3.038 .834 & 0.003761 & 0.047840 \\
\hline$S_{7}$ & $\begin{array}{l}\operatorname{ARMAX}(1,1)- \\
\operatorname{GARCH}(1,1)\end{array}$ & 0.015886 & 0.031613 & 3.019 .924 & 0.035480 & 0.038638 \\
\hline$S_{8}$ & $\begin{array}{c}\operatorname{ARMAX}(1,1)- \\
\operatorname{GARCH}(1,1)\end{array}$ & 0.017182 & 0.030165 & 3.027 .223 & 0.031832 & 0.051941 \\
\hline$S_{9}$ & $\begin{array}{l}\operatorname{ARMAX}(1,1)- \\
\operatorname{GARCH}(1,1)\end{array}$ & 0.019588 & 0.015457 & 2.900 .240 & 0.005527 & 0.034575 \\
\hline$S_{1} 0$ & $\begin{array}{l}\operatorname{ARMAX}(1,1)- \\
\operatorname{ARCH}(1,1)-\mathrm{M}\end{array}$ & 0.015356 & 0.022365 & 3.023 .342 & 0.020984 & 0.041034 \\
\hline
\end{tabular}

values, standard deviations and kurtosis for each stock $S_{1}$ up to $S_{10}$. Because the GARCH model is a symmetry (Gaussian) model, skewness is assumed to be zero. The mean estimator, standard deviation and kurtosis produced, then used to determine the MVaR values of each stock $S_{1}$ up to $S_{10}$. Based on the results of back testing, shows that the QPS value of each stock $S_{1}$ up to $S_{10}$ are in range [0,2], and tend to approach 0. This shows that MVaR under CAPM with ARMAX-GARCH approach is good enough to measure stock return risk $S_{1}$ up to $S_{10}$.

\section{Acknowledgments}

Acknowledgments are addressed to the Chancellor, Director of the Directorate of Research, Community Engagement and Innovation, and the Dean of the Faculty of Mathematics and Natural Sciences, Universitas Padjadjaran, who have provided the Universitas Padjadjaran Internal Grant Program to fund this research. This grant aims to improve research and publication activities for researchers at Universit Padjadjaran.

\section{Daftar Pustaka}

[1] Alexander V. Porshnev, A.V., Lakshina, V.V., and Redkin, I.E., 2016, Using Emotional Markers' Frequencies in Stock Market ARMAX-GARCH Model, MPRA Paper, No. 82875, pp. 1-13, Posted 23 November 2017 06:53 UTC, Online at https ://mpra.ub.uni - muenchen.de/82875/

[2] Lipiec, J., 2014, Capital Asset Pricing Model Testing at Warsaw Stock Exchange:Are Family Businesses the Remedy for Economic Recessions?, Int. J. Financial Stud, 2014, 2, 266279; doi:10.3390/ijfs2030266.

[3] Liu, K., Chen, Y.Q., and Zhang, X., 2017, An Evaluation of ARFIMA (Autoregressive Fractional Integral Moving Average) Programs, Axioms 2017, 6, 1-16, doi:10.3390/axioms6020016,

[4] Lpez-Herrera, F., Ortiz, E., and De Jess, R., 2012, Long Memory Behavior in the Returns of the Mexican Stock Market: ARFIMA Models and Value-at-Risk Estimation. International Journal of Academic 
Research in Business and Social Sciences, October 2012, Vol. 2, No. 10, pp. 113-133. ISSN: 2222-6990. www.hrmars.com/journals.

[5] Novak, J. and Dalibor, PETR., 2010, CAPM Beta, Size, Book-to-Market, and Momentum in Realized Stock Returns, Finance a vr- Czech Journal of Economics and Finance, 60, 2010, no. 5. journal.fsv.cuni.cz/.../1196 tr $_{4} 47_{4} 60-$ nov...

[6] Sembiring, F.M., Rahman, S., Effendi, N., and Sudarsono, R., 2017, Single Beta and Dual Beta Models: A Testing of CAPM on Condition of Market Overreactions. Journal of Finance and Banking Review, 2 (3) 1 7 (2017). Journal homepage: www.gatrenterprise.com/GATRJournals/index.html.

[7] Soeryana, E., Halim, N.B.A., Sukono, Rusyaman, E., and Supian, S., 2017, Mean-Variance Portfolio Optimization by Using Time Series Approaches Based on Logarithmic Utility Function. IOP Conf. Series: Materials Science and Engineering 166 (2017) 012003 doi:10.1088/1757-899X/166/1/012003.

[8] Stancu, S., 2017, Empirical Results of Modeling EUR/RON Exchange Rate Using ARCH, GARCH, EGARCH, TARCH and PARCH Models. Romanian Statistical Review nr. 1 / 2017, pp. 57-72.

[9] Skardziukas, D., 2010, Practical Approach to Estimating Cost of Capital, MPRA Paper No. 31325, posted 28. June 2011 14:02 UTC. Online at http://mpra.ub.uni-muenchen.de/31325/

[10] Sukono, Hidayat, Y., Suhartono, Sutijo, B., Bon, A.T., and Supian, S., 2016, Indonesian Financial Data Modeling and Forecasting By Using Econometrics Time Series and Neural Network. Global Journal of Pure and Applied Mathematics.ISSN 0973-1768 Volume 12, Number 4 (2016), pp. 3745-3757. Research India Publications. http ://www.ripublication.com/gjpam.htm.

[11] Sukono, Lesmana, E., Susanti, D., and Napitupulu, H., 2017, Estimating the Value-at-Risk for Some Stocks at the Capital Market in Indonesia Based on ARMA-FIGARCH Models. IOP Conf. Series: Journal of Physics: Conf. Series, 909 (2017) 012040 doi :10.1088/1742-6596/909/1/012040.

[12] Sukono, Hidayat, Y., Bon, A.T.B., and Supian, S., 2017, Modelling of Capital Asset Pricing by Considering the LaggedEffects. IOP Conf. Series: Materials Science and Engineering, 166 (2017) 012001 doi:10.1088/1757-899X/166/1/012001.

[13] Sukono, Susanti, D., Najmia, M., Lesmana, E., Napitupulu, H., Putra, A.S., and Supian, S., 2018, Analysis of Stock Investment Selection Based on CAPM Using Covariance and Genetic Algorithm Approach. IOP Conf. Series: Materials Science and Engineering, 332 (2018) 012046 doi:10.1088/1757$899 \mathrm{X} / 332 / 1 / 012046$

[14] Sukono, Hidayat, Y., Lesmana, E., Putra, A.S., Napitupulu, H., and Supian, S., 2018, Portfolio Optimization by Using Linear Programing Models Based on Genetic Algorithm. IOP Conf. Series: Materials Science and Engineering, 300 (2018) 012001 doi:10.1088/1757-899X/300/1/012001.

[15] Sukono, Sidi, P., Susanti, D., and Supian, S., 2017, Quadratic Investment Portfolio Without a Risk Free Asset Based on Value-at-Risk. Journal of Engineering and Applied Sciences, 12 (19): 4846-4850. ISSN: 1816-949X

[16] Sukono, Kartiwa, A., Subartini, B., Hidayat, Y., and Bon, A.T., 2018, Estimation of Conditional Valueat-Risk under Assets Liability Model with Non Constant Volatility. Proceedings of the International Conference on Industrial Engineering and Operations Management, Bandung, Indonesia, March 6-8, 2018, pp. 2726-2733. www.ieomsociety.org/ieom2018/

[17] Tsay, R.S., 2005, Analysis of Financial Time Series. Second Edition. Hoboken, New Jersey: John Wiley \& Sons, Inc.

[18] Dowd, K., 2002, An Introduction to Market Risk Measurement. New Delhi, India: John Wiley \& Sons, Inc. 
